\title{
KAJIAN TEORITIK INISIASI DAN PENJALARAN RETAK AKIBAT PEMBEBANAN KOMBINASI MODE I DAN MODE II
}

\section{Anwar Dolu}

\begin{abstract}
This study as a mean to find for extension direction and crack propagation, critical stress or critical crack dimension and stability of the crack path of subjected combination mode I and mode II loading. Model that assessed for crack characterize with mode combination that is Maximum Tangential Stress (MTS) and Strain Energy Density (SED). The models are referred applied at plate case with infinite length for initiation, crack growth, and critical stress of subjected biaxial, tension and compression ). Analysis result also verified with result that loading with crack angle ( has been obtained from experiment previously.
\end{abstract}

Keywords : Fracture Mechanics, Mixed-Mode, Crack Propagation, Model MTS \& SED.

\section{PENDAHULUAN}

Aplikasi struktur secara umum menerima berbagai macam pembebanan dan tegangan yaitu tegangan tarik (tension), tegangan tekan (compression), juga tegangan geser (shear) dan tegangan torsi (torsion) yang mengakibatkan adanya interaksi gabungan mode pembebanan (mixed mode interaction). Hubungannya dengan kondisi tegangan di ujung retak (crack tip) sering berdasarkan interaksi gabungan mode I dan II atau mode I dan III, yang menjelaskan besar dari tegangan pada ujung retak oleh karena pembebanan yang miring terhadap bidang retak. Selain dari pada itu, penjalaran retak dari berbagai model struktur dan bisa diperlakukan pada berbagai kondisi gabungan gaya retak (mixed mode fracture).

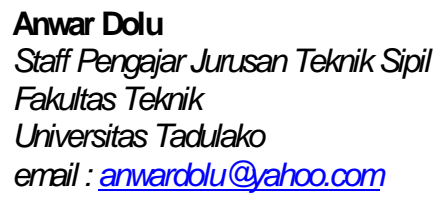


Secara umum, inisiasi retak dan pertumbuhannya berhubungan dengan faktor-faktor intensitas tegangan dalam kondisi tegangan kompleks. Artinya bahwa ujung retak merupakan bagian yang tak terpisahkan secara tiga dimensi dengan variasi ketebalan dari komponen benda padat (solid). Oleh karena itu, persamaan medan harus ditentukan dengan konsep kombinasi mode mekanika retak (mixed-mode fracture mechanics). Sebagai contoh, retak yang dibebani tegangan tarik (tension) dan tegangan geser (shear) dapat memperlihatkan pencabangan retak (crack branching) yang dapat dikarakterisasi dengan menggunakan bentuk singular dan orde tinggi dalam analisa medan tegangan. Analisa kombinasi mode dari retak yang bercabang memerlukan penentuan faktor-faktor intensitas tegangan untuk bagian awal dari retak (original crack) dan setelah terjadi penjalarannya (pencabangan retak) dalam kaitannya dengan medan tegangan di sekitar ujung retak (crack tip).

\section{Mekanika Fraktur (fracture mechanic)}

Pada mekanika fraktur melihat adanya retakan pada sebuah bahan dan memperkirakan panjang retak kritis untuk terjadinya kegagalan. Dalam bentuknya yang paling sederhana, mekanika fraktur berlaku untuk bahan yang elastik linear dengan hanya pelelehan lokal pada ujung retakan. Mekanika fraktur didasarkan pada pertimbangan energi yang diperlukan untuk pertumbuhan retakan. Energi regangan dibebaskan dari daerah tersebut, karena tidak dibebani oleh adanya retakan. Energi diperlukan untuk memecahkan ikatan atom pada ujung retakan supaya retakan kian bertambah.

Untuk suatu retakan pendek atau tingkat tegangan yang diterapkan rendah, energi yang dibebaskan tidaklah cukup untuk membangkitkan pertumbuhan retak. Kalau panjang retakan tersebut cukup (kritis), atau tingkat tegangan yang diterapkan cukup tinggi, energi yang dibebaskan menyebabkan retakan akan tumbuh secara cepat dan gagal, tanpa kenaikan tegangan yang diterapkan tersebut.

\subsection{Medan Tegangan}

Tiga jenis dari penjalaran retak yang dikenal : Mode I, pembukaan (opening mode), Mode II, geseran (sliding mode), dan Mode III, sobekan (tearing mode). Pada mode I retak disebabkan oleh tegangan tarik dalam arah y yang tegak lurus pada permukaaan retak. Pada mode II, tegangan geser bekerja tegak lurus pada tepi depan retak dan dalam bidang retak itu sendiri. Untuk mode III atau model geser sejajar, tegangan geser bekerja sejajar pada tepi depan retak. Mode I merupakan mode pembebanan yang penting. 
Distribusi tegangan pada ujung retak dalam pelat tipis (Gambar.1) diberikan pada persamaan berikut :

$$
\begin{aligned}
& \sigma_{x}=\frac{\sigma \sqrt{\mathrm{a}}}{\sqrt{2 \mathrm{r}}} \cos \frac{\theta}{2}\left\{1-\sin \frac{\theta}{2} \sin \frac{3 \theta}{2}\right\} \\
& \sigma_{\mathrm{y}}=\frac{\sigma \sqrt{\mathrm{a}}}{\sqrt{2 \mathrm{r}}} \cos \frac{\theta}{2}\left\{1+\sin \frac{\theta}{2} \sin \frac{3 \theta}{2}\right\} \\
& \tau_{\mathrm{xy}}=\frac{\sigma \sqrt{\mathrm{a}}}{\sqrt{2 \mathrm{r}}} \cos \frac{\theta}{2} \sin \frac{\theta}{2} \cos \frac{3 \theta}{2}
\end{aligned}
$$

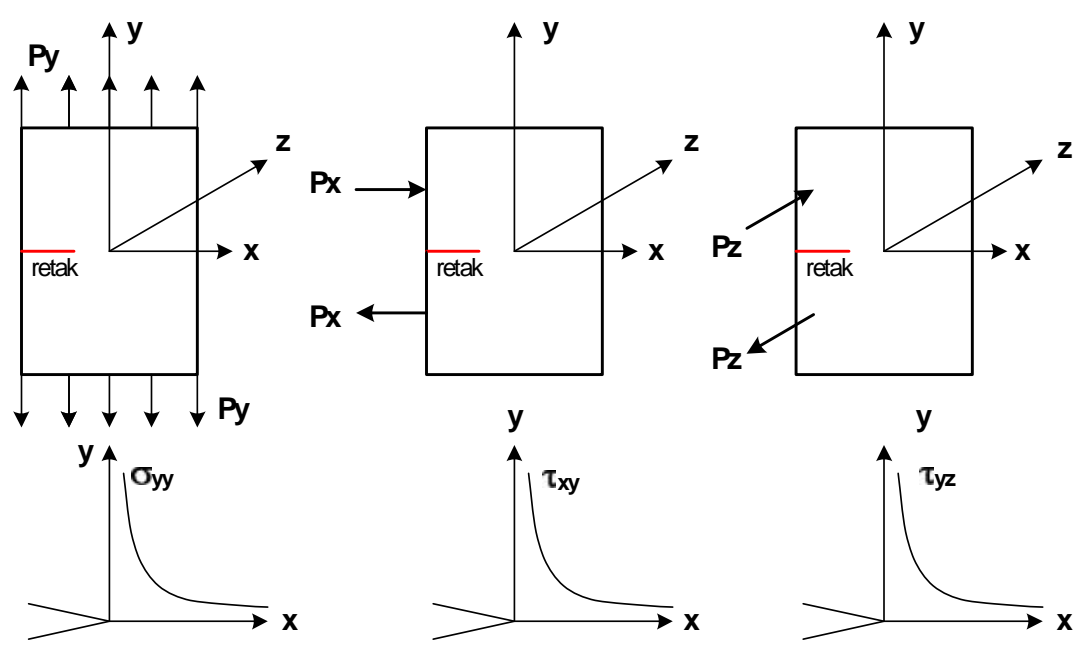

Gambar 1. Tiga Mode Pembebanan Retak

Untuk $\sigma$ adalah gaya nominal, Persamaan tersebut berlaku bila $a>r>\rho$. untuk suatu titik didepan retak $\theta=0$ maka berlaku :

$$
\sigma_{x}=\sigma_{y}=\frac{\sigma \sqrt{a}}{\sqrt{2 r}} \quad ; \quad \tau_{x y}=0
$$

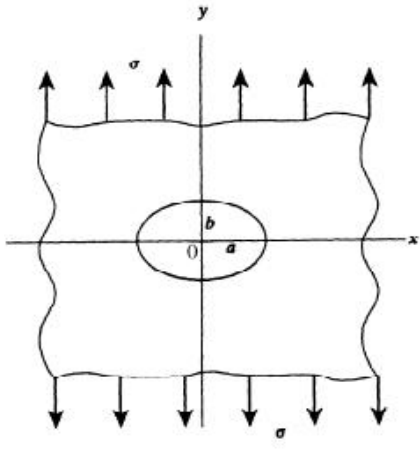

(a)

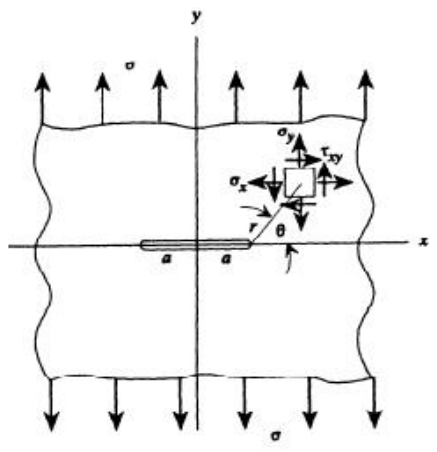

(b)

Gambar 2. (a) Lubang ellips, (b). kondisi retak (a>>b) 
Menurut Irwin (Irwin, G. 1957), Persamaan (1) menunjukan bahwa tegangan setempat dekat ujung retak tergantung pada hasil kali tegangan nominal dan akar setengah panjang retak. Hubungan ini disebut Faktor Intensitas Tegangan (stress intensity factor) K. Dalam kasus mode I dapat dituliskan sebagai $K_{1}$

$$
\mathrm{K}_{\mathrm{I}}=\sigma \sqrt{\pi \mathrm{a}}
$$

Dimensi $\mathrm{K}_{\mathrm{I}}$ adalah $(\mathrm{MPa} \sqrt{\mathrm{m}}$, atau $\mathrm{ksi} \sqrt{\mathrm{in}})$ bila nilai $\mathrm{K}_{\mathrm{I}}$ dimasukkan kedalam persaman (1), maka medan tegangan pada ujung retak menjadi :

$$
\begin{aligned}
& \sigma_{\mathrm{x}}=\frac{\mathrm{K}_{\mathrm{I}}}{\sqrt{2 \pi \mathrm{r}}} \cos \frac{\theta}{2}\left\{1-\sin \frac{\theta}{2} \sin \frac{3 \theta}{2}\right\} \\
& \sigma_{\mathrm{y}}=\frac{\mathrm{K}_{\mathrm{I}}}{\sqrt{2 \pi \mathrm{r}}} \cos \frac{\theta}{2}\left\{1+\sin \frac{\theta}{2} \sin \frac{3 \theta}{2}\right\} \\
& \tau_{\mathrm{xy}}=\frac{\mathrm{K}_{\mathrm{I}}}{\sqrt{2 \pi \mathrm{r}}} \cos \frac{\theta}{2} \sin \frac{\theta}{2} \cos \frac{3 \theta}{2}
\end{aligned}
$$

Persamaan ini menggambarkan tegangan setempat pada ujung retak dapat mencapai harga yang sangat tinggi bila $\mathrm{r} \rightarrow 0$, namun hal ini tidak terjadi karena ada deformasi plastis pada ujung retak. Faktor $\mathrm{K}$ merupakan cara yang mudah untuk membahas distribusi tegangan di sekitar retakan (crack). Nilai $\mathrm{K}$ untuk berbagai kondisi dapat dihitung dengan teori elastisitas. Untuk keadaan umum faktor intensitas tegangan $\mathrm{K}$ :

$$
\mathrm{K}_{\mathrm{I}}=\mathrm{C} \sigma \sqrt{\pi \mathrm{a}}
$$

dengan $(\mathrm{C})$ adalah parameter yang tergantung pada geometri benda uji dan ukuran retakan. Untuk kasus Mode II maka tegangan di sekitar retak sebagai berikut :

$$
\begin{aligned}
\sigma_{\mathrm{x}} & =\frac{\mathrm{K}_{\mathrm{II}}}{\sqrt{2 \pi \mathrm{r}}} \sin \frac{\theta}{2}\left(2+\cos \frac{\theta}{2} \cos \frac{3 \theta}{2}\right) \\
\sigma_{\mathrm{y}} & =\frac{\mathrm{K}_{\mathrm{II}}}{\sqrt{2 \pi \mathrm{r}}} \sin \frac{\theta}{2}\left(\cos \frac{\theta}{2} \cos \frac{3 \theta}{2}\right) \\
\tau_{\mathrm{xy}} & =\frac{\mathrm{K}_{\mathrm{II}}}{\sqrt{2 \pi \mathrm{r}}} \sin \frac{\theta}{2}\left(1-\sin \frac{\theta}{2} \sin \frac{3 \theta}{2}\right)
\end{aligned}
$$




\subsection{Ketangguhan Retak (fracture toughness) dan Desain}

Ketangguhan retak adalah sifat bahan yang menyatakan tahanan bahan terhadap retak. Ketangguhan retak bahan diperoleh dengan melakukan pengujian pada benda uji yang telah diberi retak dan dibebani sampai terjadi kegagalan. Kombinasi beban yang menyebabkan kegagalan dengan panjang retak memberikan harga ketangguhan retak bahan. Bahan yang tebal memiliki ketangguhan retak rendah. Ketangguhan retak bahan tebal disebut Ketangguhan Retak Regangan Bidang atau Kıc, ketangguhan retak bahan tipis disebut Ketangguhan Retak Tegangan Bidang atau $\mathrm{K}_{\mathrm{c}}$.

Nilai $K_{c}$ selalu lebih besar dari Kıc. Ketangguhan Retak merupakan ukuran daya tahan sebuah bahan terhadap retak, dan seperti halnya Modulus Elastisitas $(\mathrm{E})$ yang juga konstanta bahan. Dalam aplikasi pada tingkat tegangan yang diterapkan mencapai suatu tingkat kritis $\left(\sigma_{\mathrm{c}}\right)$, retakan akan menjalar secara katastropik, hal ini terjadi jika :

$$
\begin{aligned}
& \mathrm{K}_{\mathrm{I}}=\mathrm{K}_{\mathrm{IC}} \\
& \mathrm{K}_{\mathrm{IC}}=\mathrm{C} \sigma_{\mathrm{c}} \sqrt{\pi \mathrm{a}}
\end{aligned}
$$

\section{Medan Tegangan Retak dengan Kombinasi Mode (mixed mode)}

Pada banyak kajian dengan menggunakan prinsip mekanika retak berdasarkan desain dengan penggunaan dan pengembangan teori mode 1 , hal ini dimungkinkan karena kegagalan mode 1 mendominasi bahan yang isotropis. Tetapi dalam banyak kasus, pembebanan yang mungkin merupakan gabungan dari 3 mode pembebanan yaitu mode I, II dan mode III. Untuk perkiraan desain konservatif berdasarkan kriteria retak (fracture), diperlukan karakteristik retak akibat pembebanan dengan kombinasi mode (mixed mode loading).

\subsection{Permukaan Retak (fracture surface)}

Permukaan retak adalah satu tempat dari titik - titik dalam ruang $\mathrm{K}_{\mathrm{I}}-\mathrm{K}_{\mathrm{II}}$, yang merupakan aksi kombinasi dari $\mathrm{K}_{\mathrm{I}}$ dan $\mathrm{K}_{\|}$yang tergantung pada nilai kritis dari material. Untuk suatu retak dengan beban kombinasi (mixed mode loading), maka permukaan retak (fracture surface) dalam bentuk umum :

$$
\mathrm{f}\left(\mathrm{K}_{\mathrm{I}}, \mathrm{K}_{\mathrm{II}}, \mathrm{K}_{\mathrm{IC}}, \mathrm{K}_{\mathrm{IIC}}\right)=0
$$

dengan $\mathrm{K}_{\mathrm{I}}$ dan $\mathrm{K}_{\|}$adalah faktor intensitas tegangan mode I dan Mode II, $\mathrm{K}_{\mathrm{IC}}$ dan $\mathrm{K}_{\text {IIC }}$ adalah nilai kritis dari $\mathrm{K}_{\mathrm{I}}$ dan $\mathrm{K}_{\|}$. 
Fungsi dari permukaan retak :

$$
\left(\frac{\mathrm{K}_{\mathrm{I}}}{\mathrm{K}_{\mathrm{Ic}}}\right)^{\mathrm{a}}+\left(\frac{\mathrm{K}_{\mathrm{II}}}{\mathrm{K}_{\mathrm{IIc}}}\right)^{\mathrm{b}}=1
$$

Untuk konstanta a dan b tergantung dari material. Berdasarkan prinsip energi fungsi permukaan retak dapat diasumsikan dalam bentuk kuadratik dalam terminologi $K_{І}$ dan $K_{\| l}$ :

$$
\mathrm{C}_{11} \mathrm{~K}_{\mathrm{I}}^{2}+2 \mathrm{C}_{12} \mathrm{~K}_{\mathrm{I}} \mathrm{K}_{\mathrm{II}}+\mathrm{C}_{22} \mathrm{~K}_{\mathrm{II}}^{2}=\mathrm{C}
$$

$\mathrm{C}_{11}, \mathrm{C}_{12}$ dan $\mathrm{C}_{22}$ merupakan konstanta material yang diperoleh dari hasil eksperimen dan $\mathrm{C}$ adalah konstanta riil. Hasil Eksperimen dari Erdogan dan Sih untuk distribusinya berbentuk ellips. Jenis distribusi tersebut diberikan Pers. (10).

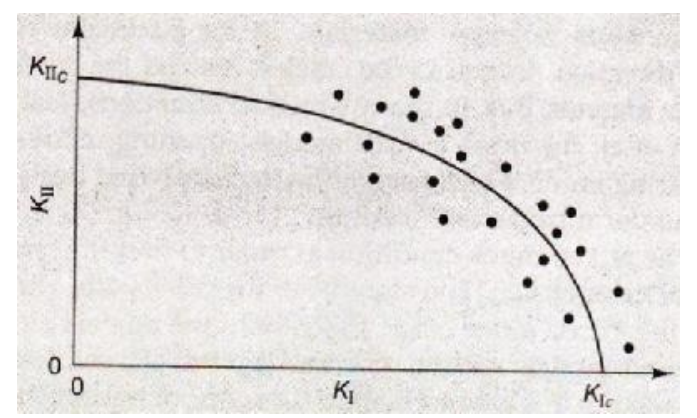

Gambar 3. Tipical Permukaan fraktur (Kumar, 2009)

Broek mengusulkan model berikut :

$$
\left(\frac{\mathrm{K}_{\mathrm{I}}}{\mathrm{K}_{\mathrm{Ic}}}\right)^{2}+\left(\frac{\mathrm{K}_{\mathrm{II}}}{\mathrm{K}_{\mathrm{IIc}}}\right)^{2}=1
$$

Hasil observasi dari Broek bahwa permukaan retak Pers. (11) mendekati perilaku dari kombinasi mode (mixed mode) untuk banyak kasus jenis material.

\section{Penjalaran Retak dengan Kombinasi Mode}

Tinjauan kasus kombinasi mode I dan mode I| diakibatkan oleh tegangan tarik (tension) maupun tegangan geser (shear), yang masing-masing dapat berupa superposisi tegangan tarik maupun 
tegangan geser atau dapat pula hanya dibebani tegangan tarik aksial tapi membentuk sudut $\beta$ pada bidang retak maka akan tetap terjadi aksi kombinasi mode I dan Mode II tersebut.

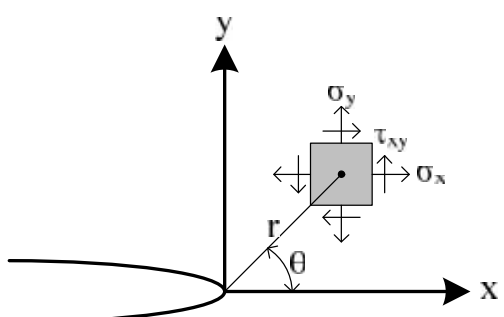

a. Koordinat Kartesian $(x, y)$

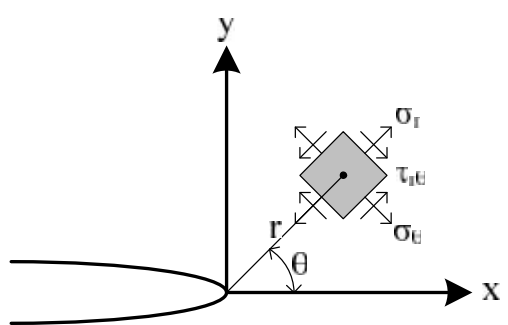

b. Koordinat Polar $(r, \theta)$

Gambar 4. Komponen Tegangan di sekitar ujung retak

Kombinasi Mode I dan Mode II dalam koordinat kartesian (Gambar. 4a)

$$
\begin{aligned}
& \sigma_{\mathrm{x}}=\frac{1}{\sqrt{2 \pi \mathrm{r}}}\left[\mathrm{K}_{\mathrm{I}} \cos \frac{\theta}{2}\left(1-\sin \frac{\theta}{2} \sin \frac{3 \theta}{2}\right)-\mathrm{K}_{\mathrm{II}} \sin \frac{\theta}{2}\left(2+\cos \frac{\theta}{2} \cos \frac{3 \theta}{2}\right)\right] \\
& \sigma_{\mathrm{y}}=\frac{1}{\sqrt{2 \pi \mathrm{r}}}\left[\mathrm{K}_{\mathrm{I}} \cos \frac{\theta}{2}\left(1+\sin \frac{\theta}{2} \sin \frac{3 \theta}{2}\right)+\mathrm{K}_{\mathrm{II}} \sin \frac{\theta}{2}\left(\cos \frac{\theta}{2} \cos \frac{3 \theta}{2}\right)\right] \\
& \tau_{\mathrm{xy}}=\frac{1}{\sqrt{2 \pi \mathrm{r}}}\left[\mathrm{K}_{\mathrm{I}} \cos \frac{\theta}{2}\left(\cos \frac{\theta}{2} \cos \frac{3 \theta}{2}\right)+\mathrm{K}_{\mathrm{II}} \sin \frac{\theta}{2}\left(1-\sin \frac{\theta}{2} \sin \frac{3 \theta}{2}\right)\right]
\end{aligned}
$$

Dalam bentuk koordinat polar seperti gambar $4 b$.

$$
\begin{aligned}
\sigma_{\mathrm{r}} & =\frac{1}{\sqrt{2 \pi \mathrm{r}}}\left[\mathrm{K}_{\mathrm{I}}\left(\frac{5}{4} \cos \frac{\theta}{2}-\frac{1}{4} \cos \frac{3 \theta}{2}\right)+\mathrm{K}_{\mathrm{II}}\left(-\frac{5}{4} \sin \frac{\theta}{2}+\frac{3}{4} \sin \frac{3 \theta}{2}\right)\right] \\
\sigma_{\theta} & =\frac{1}{\sqrt{2 \pi \mathrm{r}}} \cos \frac{\theta}{2}\left(\mathrm{~K}_{\mathrm{I}} \cos ^{2} \frac{\theta}{2}-\frac{3}{2} \mathrm{~K}_{\mathrm{II}} \sin \theta\right) \\
\tau_{\mathrm{r} \theta} & =\frac{1}{2 \sqrt{2 \pi \mathrm{r}}} \cos \frac{\theta}{2}\left[\mathrm{~K}_{\mathrm{I}} \sin \theta+\mathrm{K}_{\mathrm{II}}(3 \cos \theta-1)\right]
\end{aligned}
$$

\subsubsection{Tegangan Tangensial Maksimum (Maximum Tangential Stress, MTS)}

Kriteria ini diusulkan oleh Erdogan dan Sih berdasarkan asumsi bahwa permulaan retak (crack initiates) terjadi pada ujung arah normal dari tegangan melingkar maksimum $\sigma_{\theta}$. Dari gbr 5 retak miring dengan sudut $\beta$ terhadap arah tegangan utama yang dibebani tegangan $\sigma b$ dan $\tau b$. Faktor intensitas tegangan biaxial (Shah, P Surendra, 1995) adalah : 


$$
\begin{aligned}
& \mathrm{K}_{\mathrm{I}}=\left[\frac{1}{2}\left(\sigma_{1}+\sigma_{2}\right)+\frac{1}{2}\left(\sigma_{1}-\sigma_{2}\right) \cos (2 \beta)\right] \sqrt{\pi \mathrm{a}} \\
& \mathrm{K}_{\mathrm{II}}=\left[\frac{1}{2}\left(\sigma_{2}-\sigma_{1}\right) \sin (2 \beta)\right] \sqrt{\pi \mathrm{a}}
\end{aligned}
$$

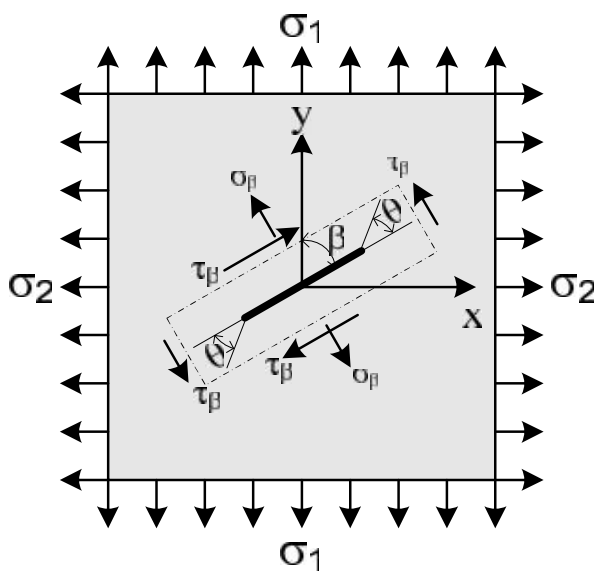

Gambar 5. Sudut Retak $\beta$ dengan Tegangan Biaxial

Dengan mengambil $\mathrm{m}_{\mathrm{s}}=\sigma_{2} / \sigma_{1}$ dari tegangan utama, maka persamaan 14 sebelumnya dapat dituliskan sebagai berikut :

$$
\begin{aligned}
& \mathrm{K}_{\mathrm{I}}=\sigma_{2} \sqrt{\pi \mathrm{a}}\left[\mathrm{m}_{\mathrm{s}}+\left(1-\mathrm{m}_{\mathrm{s}}\right) \sin ^{2} \beta\right] \\
& \mathrm{K}_{\mathrm{II}}=\sigma_{2} \sqrt{\pi \mathrm{a}}\left(1-\mathrm{m}_{\mathrm{s}}\right) \sin \beta \cos \beta
\end{aligned}
$$

Kasus retak yang dibebani Mode I dan Mode II, maka komponen tegangan disekitar ujung retak (titik H) pada gambar 6 dengan menggunakan koordinat kutub dinyatakan sebagai :

$$
\begin{aligned}
& \sigma_{\mathrm{rr}}=\mathrm{K}_{\mathrm{I}} \mathrm{f}_{11}(\mathrm{r}, \theta)+\mathrm{K}_{\mathrm{II}} \mathrm{f}_{12}(\mathrm{r}, \theta) \\
& \sigma_{\theta \theta}=\mathrm{K}_{\mathrm{I}} \mathrm{f}_{21}(\mathrm{r}, \theta)+\mathrm{K}_{\mathrm{II}} \mathrm{f}_{22}(\mathrm{r}, \theta) \\
& \tau_{\mathrm{r} \theta}=\mathrm{K}_{\mathrm{I}} \mathrm{f}_{31}(\mathrm{r}, \theta)+\mathrm{K}_{\mathrm{II}} \mathrm{f}_{32}(\mathrm{r}, \theta)
\end{aligned}
$$

Dengan fungsi $f_{i j}(r, \theta)$ sesuai Persamaan 17 berikut :

$$
\begin{aligned}
& \mathrm{f}_{11}(\mathrm{r}, \theta)=\frac{1}{\sqrt{2 \pi \mathrm{r}}}\left(\frac{5}{4} \cos \frac{\theta}{2}-\frac{1}{4} \cos \frac{3 \theta}{2}\right) ; \mathrm{f}_{12}(\mathrm{r}, \theta)=\frac{1}{\sqrt{2 \pi \mathrm{r}}}\left(-\frac{5}{4} \sin \frac{\theta}{2}+\frac{3}{4} \sin \frac{3 \theta}{2}\right) \\
& \mathrm{f}_{21}(\mathrm{r}, \theta)=\frac{1}{\sqrt{2 \pi \mathrm{r}}}\left(\frac{3}{4} \cos \frac{\theta}{2}+\frac{1}{4} \cos \frac{3 \theta}{2}\right) ; \mathrm{f}_{22}(\mathrm{r}, \theta)=\frac{1}{\sqrt{2 \pi \mathrm{r}}}\left(-\frac{3}{4} \cos \frac{\theta}{2}-\frac{3}{4} \cos \frac{3 \theta}{2}\right) 17 \\
& \mathrm{f}_{31}(\mathrm{r}, \theta)=\frac{1}{\sqrt{2 \pi \mathrm{r}}}\left(\frac{1}{4} \sin \frac{\theta}{2}+\frac{1}{4} \sin \frac{3 \theta}{2}\right) ; \mathrm{f}_{32}(\mathrm{r}, \theta)=\frac{1}{\sqrt{2 \pi \mathrm{r}}}\left(\frac{1}{4} \cos \frac{\theta}{2}+\frac{3}{4} \cos \frac{3 \theta}{2}\right)
\end{aligned}
$$




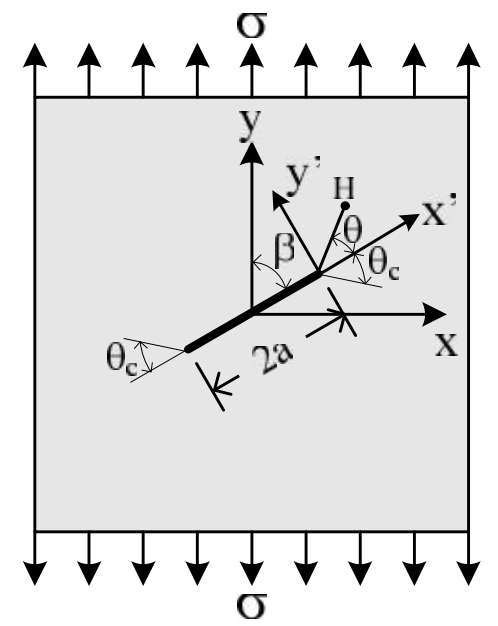

Gambar 6. Retak dengan sudut $\beta$ dibebani beban aksial

\section{Arah perambatan retak (crack extension direction)}

$$
\begin{aligned}
& \frac{\partial \sigma_{\theta \theta}}{\partial \theta}=0 \\
& \frac{\partial^{2} \sigma_{\theta \theta}}{\partial \theta^{2}}<0
\end{aligned}
$$

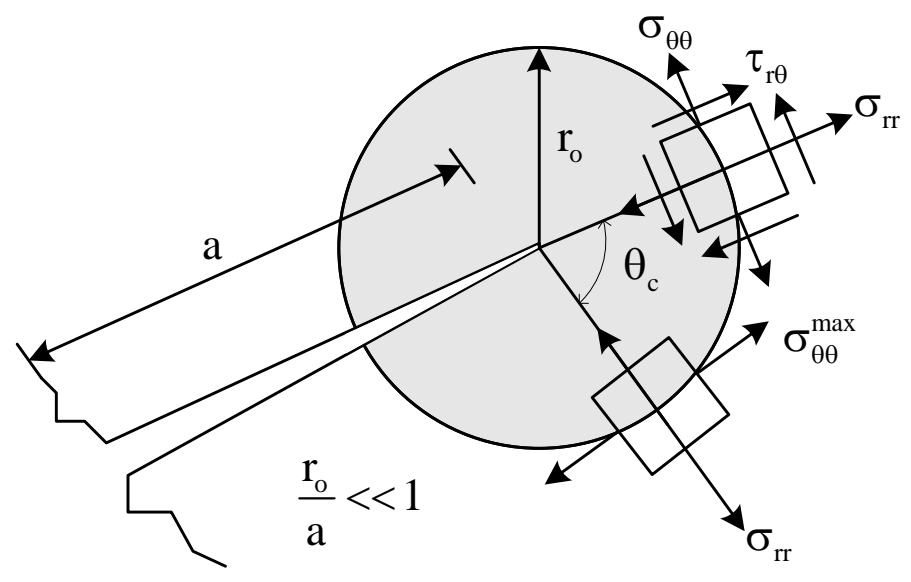

Gambar 7. Perpanjangan Retak Teori MTS (Kumar, 2009)

Dengan subtitusi $\mathrm{f}_{21}(\mathrm{r}, \theta)$ dan $\mathrm{f}_{22}(\mathrm{r}, \theta)$ ke persamaan 16.b, maka diperoleh :

$$
\sigma_{\theta \theta}=\frac{\mathrm{K}_{\mathrm{I}}}{4 \sqrt{2 \pi \mathrm{r}}}\left(3 \cos \frac{\theta}{2}+\cos \frac{3 \theta}{2}\right)-\frac{\mathrm{K}_{\mathrm{II}}}{4 \sqrt{2 \pi \mathrm{r}}}\left(\sin \frac{\theta}{2}+\sin \frac{3 \theta}{2}\right)
$$

Dengan kondisi berdasar Pers. 18.a :

$$
\frac{\partial \sigma_{\theta \theta}}{\partial \theta}=\mathrm{K}_{\mathrm{I}}\left(-\frac{3}{2} \sin \frac{\theta}{2}-\frac{3}{2} \sin \frac{3 \theta}{2}\right)-3 \mathrm{~K}_{\mathrm{II}}\left(\frac{1}{2} \cos \frac{\theta}{2}+\frac{3}{2} \cos \frac{3 \theta}{2}\right)=0
$$


Maka diperoleh :

$$
\begin{aligned}
& \mathrm{K}_{\mathrm{I}}\left(\sin \frac{\theta_{\mathrm{c}}}{2}+\sin \frac{3 \theta_{\mathrm{c}}}{2}\right)+\mathrm{K}_{\mathrm{II}}\left(\cos \frac{\theta_{\mathrm{c}}}{2}+3 \cos \frac{3 \theta_{\mathrm{c}}}{2}\right)=0 \\
& 4 \cos \frac{\theta_{\mathrm{c}}}{2}\left[\mathrm{~K}_{\mathrm{I}}\left(\sin \frac{\theta_{\mathrm{c}}}{2} \cos \frac{\theta_{\mathrm{c}}}{2}\right)+\mathrm{K}_{\mathrm{II}}\left(3 \cos ^{2} \frac{\theta_{\mathrm{c}}}{2}-2\right)\right]=0 \\
& 2 \cos \frac{\theta_{\mathrm{c}}}{2}\left[\mathrm{~K}_{\mathrm{I}} \sin \theta_{\mathrm{c}}+\mathrm{K}_{\mathrm{II}}\left(3 \cos \theta_{\mathrm{c}}-1\right)\right]=0
\end{aligned}
$$

Dengan penyederhanaan maka diperoleh :

$$
\mathrm{K}_{\mathrm{I}} \sin \theta_{\mathrm{c}}+\mathrm{K}_{\mathrm{II}}\left(3 \cos \theta_{\mathrm{c}}-1\right)=0
$$

Penyelesaian dari bentuk pers. (20) dalam bentuk sudut kritis $(\theta c)$ :

$$
\begin{array}{ll}
\theta_{\mathrm{c}}=0 & \text { jika } \mathrm{K}_{\mathrm{II}}=0, \\
\theta_{\mathrm{c}}=2 \arctan \left[\frac{1}{4} \frac{\mathrm{K}_{\mathrm{I}}}{\mathrm{K}_{\mathrm{II}}} \pm \frac{1}{4} \sqrt{\left(\frac{\mathrm{K}_{\mathrm{I}}}{\mathrm{K}_{\mathrm{II}}}\right)^{2}+8}\right] \quad \text { jika } \mathrm{K}_{\mathrm{II}} \neq 0
\end{array}
$$

\section{Kondisi kritis}

Untuk $\sigma_{\theta \theta}^{\max }$ adalah nilai maksimum dari $\sigma_{\theta \theta}$ yang berhubungan dengan arah perpanjangan retak, subtitusi nilai $\theta$ dengan $\theta_{c}$ pada Pers. (19), maka diperoleh :

$$
\sigma_{\theta \theta}^{\max }=\frac{\mathrm{K}_{\mathrm{I}}}{4 \sqrt{2 \pi \mathrm{r}_{\mathrm{o}}}} \cos ^{3} \frac{\theta_{\mathrm{c}}}{2}-\frac{3 \mathrm{~K}_{\mathrm{II}}}{2 \sqrt{2 \pi \mathrm{r}_{\mathrm{o}}}} \cos \frac{\theta_{\mathrm{c}}}{2} \sin \theta_{\mathrm{c}}
$$

Perpanjangan retak terjadi ketika $\sigma_{\theta \theta}^{\max }$ mencapai suatu nilai kritis $\sigma_{c}$ dimana hanya tergantung dari material. $\sigma_{c}$ dengan beban mode I dimana $\theta c=0$ dan $\mathrm{K}_{\mathrm{I}}=\mathrm{K}_{\mathrm{Ic}}$ maka :

$$
\sigma_{\mathrm{c}}=\frac{\mathrm{K}_{\mathrm{Ic}}}{\sqrt{2 \pi \mathrm{r}_{\mathrm{o}}}}
$$

Untuk medapatkan kegagalan permukaan (failure surface) yang independen dari jarak ro, dengan subtitusi Pers. (24) ke Pers. 23, maka diperoleh :

$$
\mathrm{K}_{\mathrm{I}} \cos ^{3} \frac{\theta_{\mathrm{c}}}{2}-\frac{3}{2} \mathrm{~K}_{\mathrm{II}} \cos \frac{\theta_{\mathrm{c}}}{2} \sin \theta_{\mathrm{c}}=\mathrm{K}_{\mathrm{Ic}}
$$


Dengan mengumpulkan kembali Pers. (21) dan Pers. (25), serta manipulasi aljabar membagi persamaan tersebut dengan $\mathrm{K}_{\mathrm{Ic}}$, serta mendefinisikan $\mathrm{KI}^{\star}$ dan $\mathrm{KII}^{\star}$

$$
\mathrm{K}_{\mathrm{I}}^{*}=\frac{\mathrm{K}_{\mathrm{I}}}{\mathrm{K}_{\mathrm{Ic}}} \quad \mathrm{K}_{\mathrm{II}}^{*}=\frac{\mathrm{K}_{\mathrm{II}}}{\mathrm{K}_{\mathrm{IIc}}}
$$

Maka diperoleh persamaan simultan berikut :

$$
\begin{aligned}
& \mathrm{K}_{\mathrm{I}}^{*} \sin \theta+\mathrm{K}_{\mathrm{II}}^{*}(3 \cos \theta-1)=0 \\
& {\left[\mathrm{~K}_{\mathrm{I}}^{*} \cos ^{2}(\theta / 2)-\frac{3}{2} \mathrm{~K}_{\mathrm{II}}^{*} \sin \theta\right] \cos (\theta / 2)=1}
\end{aligned}
$$

Dengan menyelesaikan persamaan simultan tersebut, maka diperoleh :

$$
\begin{aligned}
\mathrm{K}_{\mathrm{I}}^{*} & =\frac{3 \cos ^{2}(\theta / 2)-2}{\cos ^{3}(\theta / 2)} \\
\mathrm{K}_{\mathrm{II}}^{*} & =-\frac{3 \sin (\theta / 2)}{\cos ^{2}(\theta / 2)}
\end{aligned}
$$

Berdasarkan Persamaan (28) maka dapat dihitung dan dibuat grafik Fraktur Locus (Gbr. 8) serta hubungan sudut retak $(\beta)$ dan sudut penjalaran retak $(\theta)$ untuk kriteria MTS berdasarkan persamaan (21) sesuai Gbr.9. 


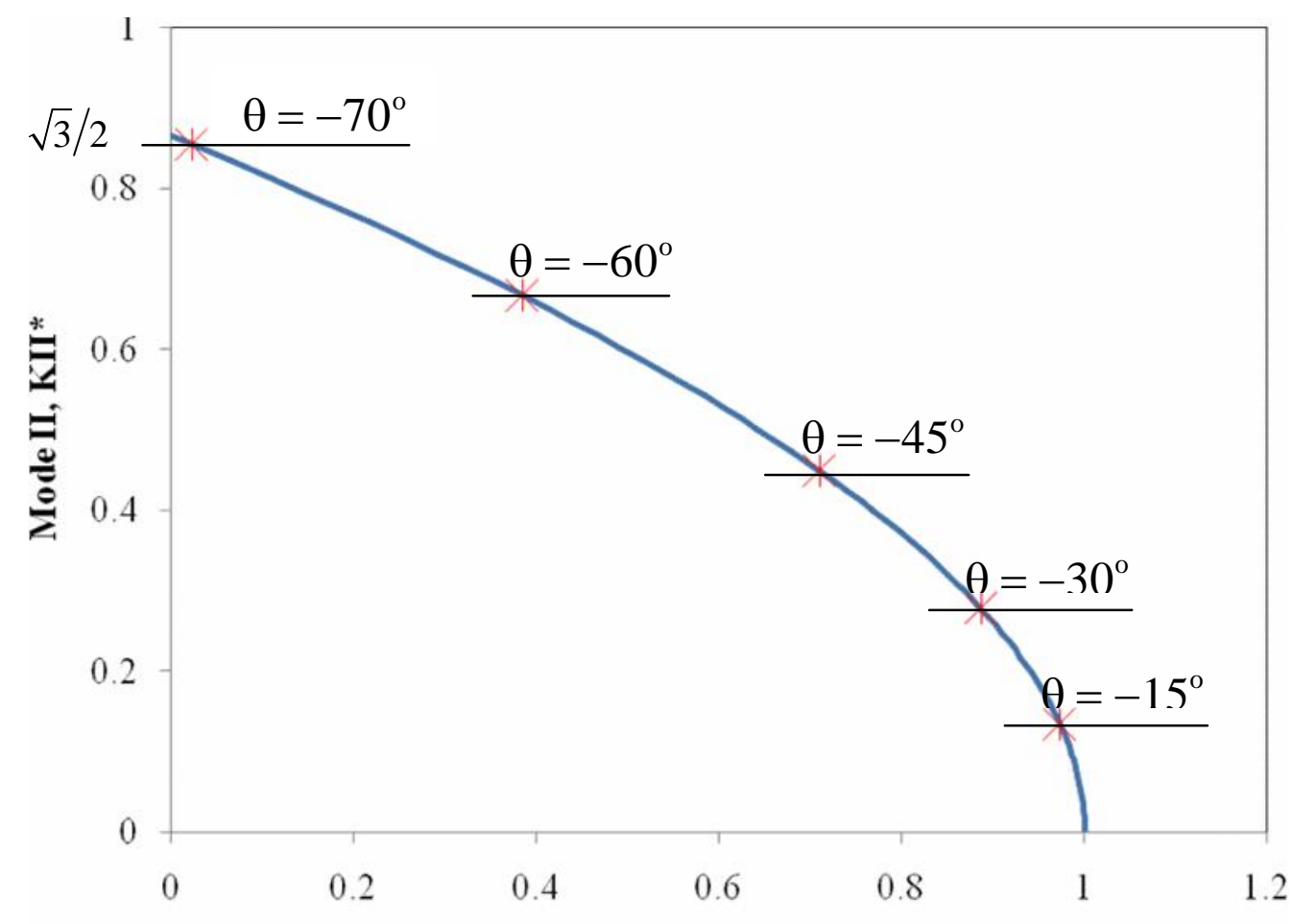

Mode I, KI*

Gambar 8. Fraktur locus, Kriteria MTS (Pers. 28)

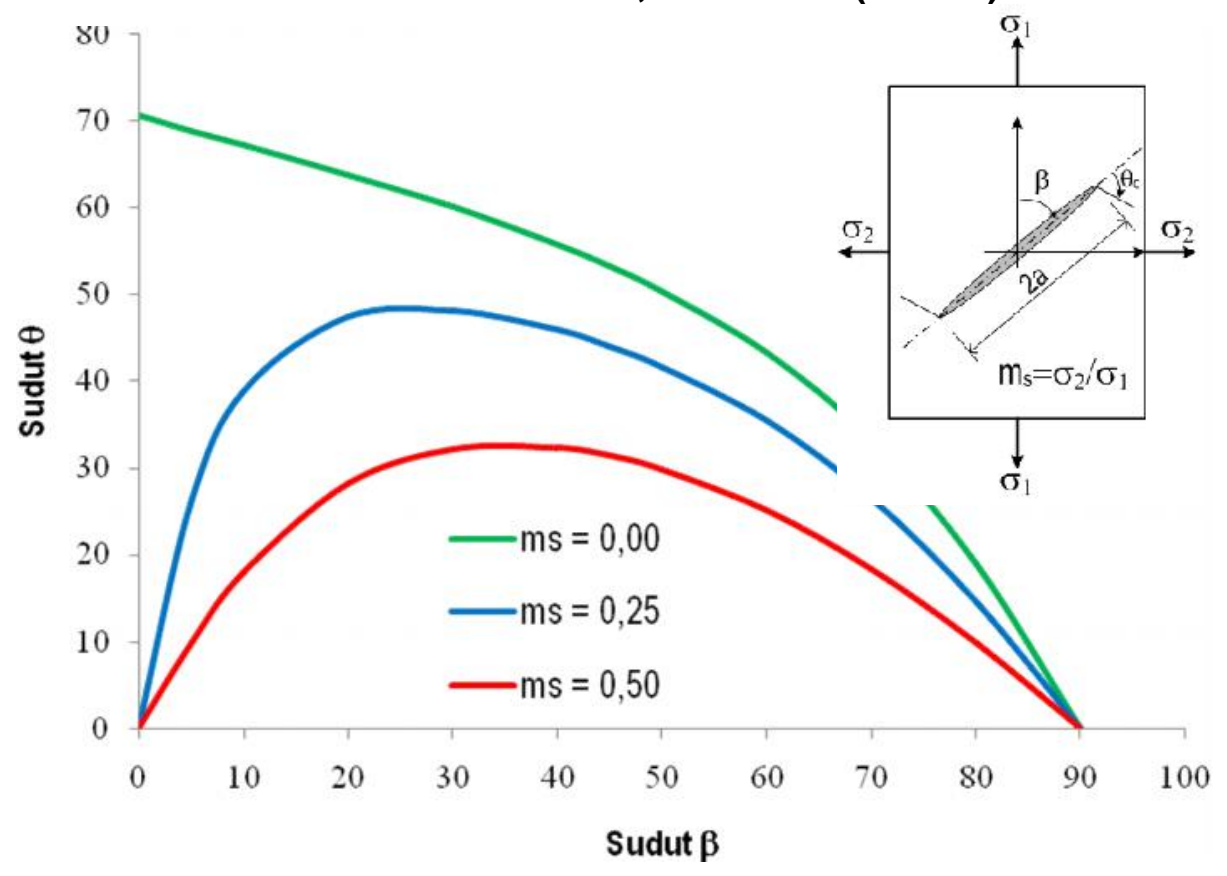

Gambar 9. Hubungan sudut $\beta$ dan $\theta$ Kriteria MTS, variasi $\mathrm{m}_{\mathbf{s}}$ (Pers.21)

\subsubsection{Kerapatan Energi Regangan (Strain Energy Density, SED)}

Berdasarkan prinsip energi, George C. Sih mengusulkan kriteria Kerapatan Energi Regangan (Strain Energy Density, SED). Sebuah retakan yang mengalami pembebanan Mode I dan Mode II seperti 
gambar 6 , maka total energi regangan $U$ dapat dituliskan dalam bentuk medan tegangan dan regangan

$$
\mathrm{U}=\int_{\mathrm{V}}\left[\int_{0}^{\varepsilon \mathrm{ij}}\left(\sigma_{\mathrm{ij}} \mathrm{d} \varepsilon_{\mathrm{ij}}\right)\right] \mathrm{dV}
$$

Fungsi Kerapatan Energi Regangan (Strain Energy Density) W diberikan berikut :

$$
\mathrm{W}=\frac{\mathrm{dU}}{\mathrm{dV}}=\int_{\mathrm{V}}\left(\sigma_{\mathrm{ij}} \mathrm{d} \varepsilon_{\mathrm{ij}}\right)
$$

Pada kasus bidang maka fungsi W dapat ditulis kembali dalam terminologi tegangan :

$$
\mathrm{W}=\frac{(1+v)}{2 \mathrm{E}}\left[\frac{(\kappa+1)}{4}\left(\sigma_{11}+\sigma_{22}\right)^{2}-2\left(\sigma_{11} \sigma_{22}-\tau_{12}^{2}\right)\right]
$$

Untuk $\kappa$ masing-masing regangan bidang dan tegangan bidang :

$$
\begin{aligned}
& \kappa=3-4 v \\
& \kappa=(3-v) /(1+v)
\end{aligned}
$$

Komponen tegangan dalam terminologi sistem koordinat kutub :

$$
\begin{aligned}
& \sigma_{11}=\mathrm{K}_{\mathrm{I}} \mathrm{f}_{11}(\mathrm{r}, \theta)+\mathrm{K}_{\mathrm{II}} \mathrm{f}_{12}(\mathrm{r}, \theta) \\
& \sigma_{22}=\mathrm{K}_{\mathrm{I}} \mathrm{f}_{21}(\mathrm{r}, \theta)+\mathrm{K}_{\mathrm{II}} \mathrm{f}_{22}(\mathrm{r}, \theta) \\
& \tau_{12}=-\mathrm{K}_{\mathrm{I}} \mathrm{f}_{31}(\mathrm{r}, \theta)+\mathrm{K}_{\mathrm{II}} \mathrm{f}_{32}(\mathrm{r}, \theta)
\end{aligned}
$$

dengan fungsi $f_{i j}(r, \theta)$ pada persamaan 34 berikut :

$$
\begin{aligned}
& \mathrm{f}_{11}(\mathrm{r}, \theta)=\frac{1}{\sqrt{2 \pi \mathrm{r}}} \cos \frac{\theta}{2}\left(1-\sin \frac{\theta}{2} \sin \frac{3 \theta}{2}\right) ; \mathrm{f}_{12}(\mathrm{r}, \theta)=-\frac{1}{\sqrt{2 \pi \mathrm{r}}} \sin \frac{\theta}{2}\left(2+\cos \frac{\theta}{2} \cos \frac{3 \theta}{2}\right) \\
& \mathrm{f}_{21}(\mathrm{r}, \theta)=\frac{1}{\sqrt{2 \pi \mathrm{r}}} \cos \frac{\theta}{2}\left(1+\sin \frac{\theta}{2} \sin \frac{3 \theta}{2}\right) ; \mathrm{f}_{22}(\mathrm{r}, \theta)=\frac{1}{\sqrt{2 \pi \mathrm{r}}} \sin \frac{\theta}{2} \cos \frac{\theta}{2} \cos \frac{3 \theta}{2} \\
& \mathrm{f}_{31}(\mathrm{r}, \theta)=\frac{1}{\sqrt{2 \pi \mathrm{r}}} \sin \frac{\theta}{2} \cos \frac{\theta}{2} \cos \frac{3 \theta}{2} ; \mathrm{f}_{32}(\mathrm{r}, \theta)=\frac{1}{\sqrt{2 \pi \mathrm{r}}} \cos \frac{\theta}{2}\left(1-\sin \frac{\theta}{2} \sin \frac{3 \theta}{2}\right)
\end{aligned}
$$


Subtitusi persamaan 33a, 33b, 33c ke Pers. 31, maka fungsi SED diperoleh dengan penyederhanaan dalam kaitannya dengan faktor intensitas tegangan $(\mathrm{K})$ :

$$
\mathrm{W}=\frac{1}{\pi \mathrm{r}}\left(\mathrm{g}_{11} \mathrm{~K}_{\mathrm{I}}^{2}+2 \mathrm{~g}_{12} \mathrm{~K}_{\mathrm{I}} \mathrm{K}_{\mathrm{II}}+\mathrm{g}_{22} \mathrm{~K}_{\mathrm{II}}^{2}\right)
$$

Dimana :

$$
\begin{aligned}
& \mathrm{g}_{11}=\frac{1}{16 \mu}(1+\cos \theta)(\kappa-\cos \theta) \\
& \mathrm{g}_{12}=\frac{1}{16 \mu}(\sin \theta)[2 \cos \theta-(\kappa-1)] \\
& \mathrm{g}_{22}=\frac{1}{16 \mu}(\sin \theta)[(\kappa+1)(1-\cos \theta)+(1+\cos \theta)(3 \cos \theta-1)] \\
& \mu=\mathrm{E} /[2(1+v)]
\end{aligned}
$$

Fungsi Kerapatan Energi Regangan menunjukan nilai singular (singularity) diujung retak. Sih mengusulkan Fungsi Kerapatan Energi Regangan S dalam bentuk kuadrat yang independen terhadap koordinat $r$ yang didefinisikan sebagai :

$$
\mathrm{S}(\theta)=\frac{1}{\pi}\left(\mathrm{g}_{11} \mathrm{~K}_{\mathrm{I}}^{2}+2 \mathrm{~g}_{12} \mathrm{~K}_{\mathrm{I}} \mathrm{K}_{\mathrm{II}}+\mathrm{g}_{22} \mathrm{~K}_{\mathrm{II}}^{2}\right)
$$

\section{Arah perambatan retak (crack extension direction)}

Dengan mempertimbangkan pembebanan kombinasi sesuai gambar 6 , sepanjang keliling lingkaran dari jari - jari $r_{0}$, maka kerapatan energi regangan yang diminimasi dan berhubungan dengan fungsi sudut krits $\theta_{c}$ yang dievaluasi dengan kondisi :

$$
\begin{aligned}
& \frac{\partial S}{\partial \theta}=0 \\
& \frac{\partial^{2} S}{\partial \theta^{2}}>0
\end{aligned}
$$

Subtitusi pers. 37 ke persamaan 38, maka diperoleh :

$$
\begin{aligned}
& {[2 \cos \theta-(\kappa-1)](\sin \theta) \mathrm{K}_{\mathrm{I}}^{2}+2[2 \cos 2 \theta-(\kappa-1) \cos \theta] \mathrm{K}_{\mathrm{I}} \mathrm{K}_{\mathrm{II}}} \\
& +[(\kappa-1-6 \cos \theta) \sin \theta] \mathrm{K}_{\mathrm{II}}^{2}=0 \\
& {[2 \cos 2 \theta-(\kappa-1) \cos \theta] \mathrm{K}_{\mathrm{I}}^{2}+2[(\kappa-1) \sin \theta-4 \sin 2 \theta] \mathrm{K}_{\mathrm{I}} \mathrm{K}_{\mathrm{II}}} \\
& +[(\kappa-1) \cos \theta-6 \cos 2 \theta] \mathrm{K}_{\mathrm{II}}^{2}>0
\end{aligned}
$$




\section{Kondisi kritis}

Pertambahan panjang akan akan terjadi saat nilai minimum dari fungsi kerapatan energi regangan $\left(\mathrm{S}_{\mathrm{min}}\right)$. Kondisi kritis dalam bentuk :

$$
\mathrm{S}_{\min } \geq \mathrm{S}_{\mathrm{c}}
$$

nilai kritis Sc bergantung dari material dapat diperoleh dari Pers. 37 untuk beban Mode I murni dengan $\theta \mathrm{c}=0^{\circ}$ dan $\mathrm{K}_{\mathrm{I}}=\mathrm{K}_{\mathrm{Ic}}$ maka :

$$
\mathrm{S}_{\mathrm{c}}=\frac{(1+v)(\kappa-1)}{4 \pi \mathrm{E}} \mathrm{K}_{\mathrm{Ic}}^{2}
$$

Dari ketidaksamaan Pers. (40) dapat dinyatakan sebagai :

$$
\mathrm{S}_{\min } \geq \frac{(1+v)(\kappa-1)}{4 \pi \mathrm{E}} \mathrm{K}_{\mathrm{Ic}}^{2}
$$

Berdasarkan Persamaan 39a dan Persamaan 39b dapat dihitung dan dibuat grafik hubungan $\mathrm{KI}^{\star}$ dan $\mathrm{KII}{ }^{\star}$ seperti pada gambar 10 dengan variasi $\mathrm{v}=0,10 ; 0,30$. 


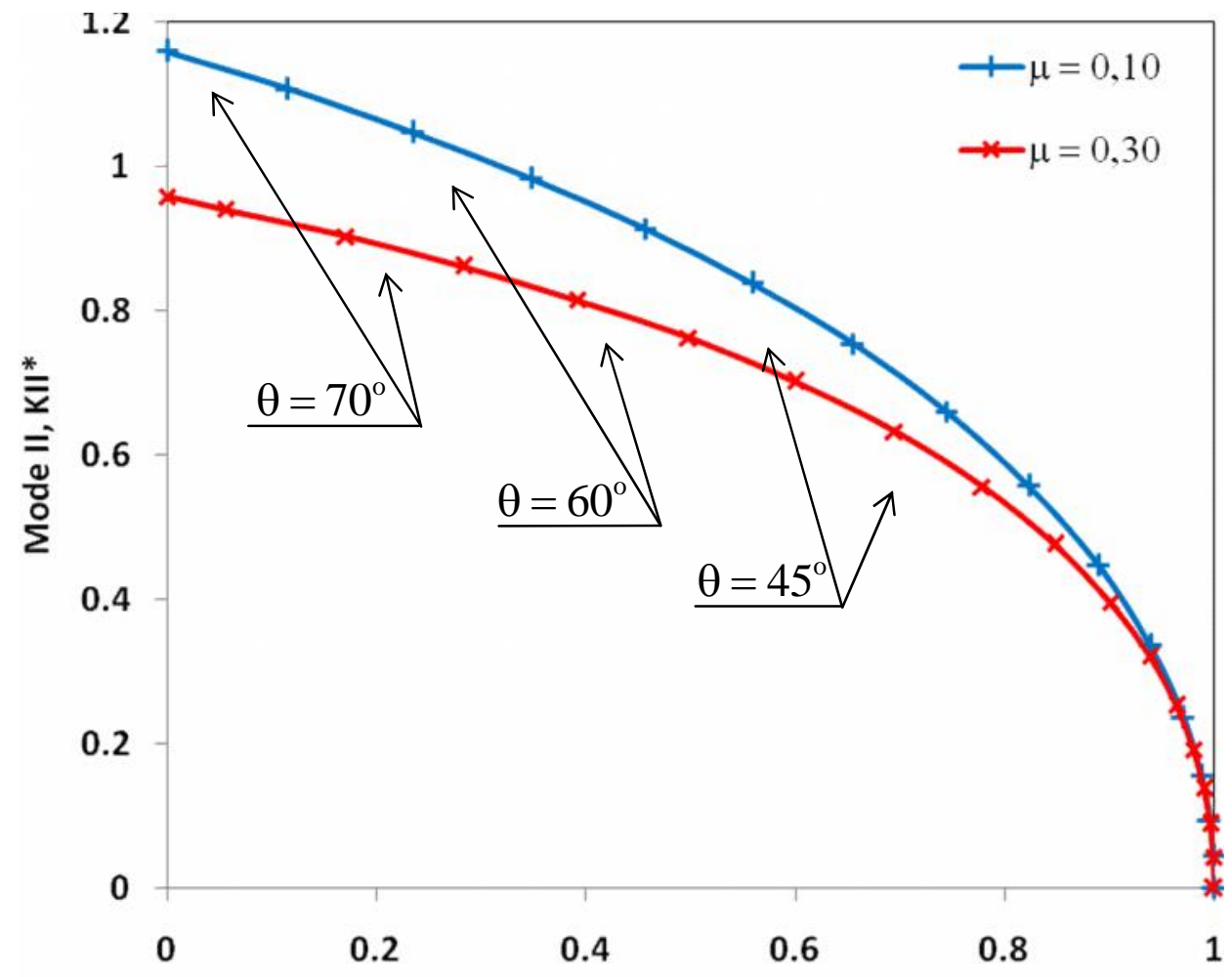

Mode I, KI*

Gambar 10. Hubungan $\mathrm{KI}^{\star}$ dan KII* Kriteria SED

Dari pers. 39a dapat dibuat hubungan sudut $\beta$ dan $\theta$ dengan variasi ms dan $v$ tetap $(v=0,30)$ seperti pada gambar 11.

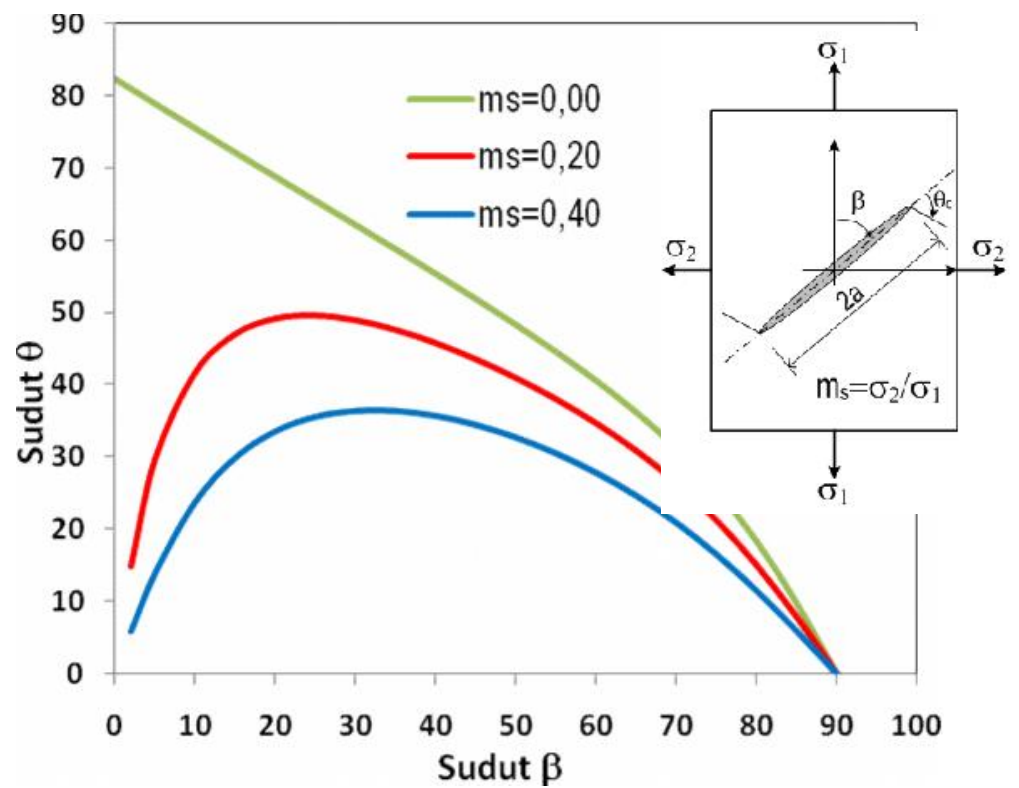

Gambar 11. Hubungan sudut $\beta$ dan $\theta$ Kriteria SED $(v=0,30$, Pers.39a) 


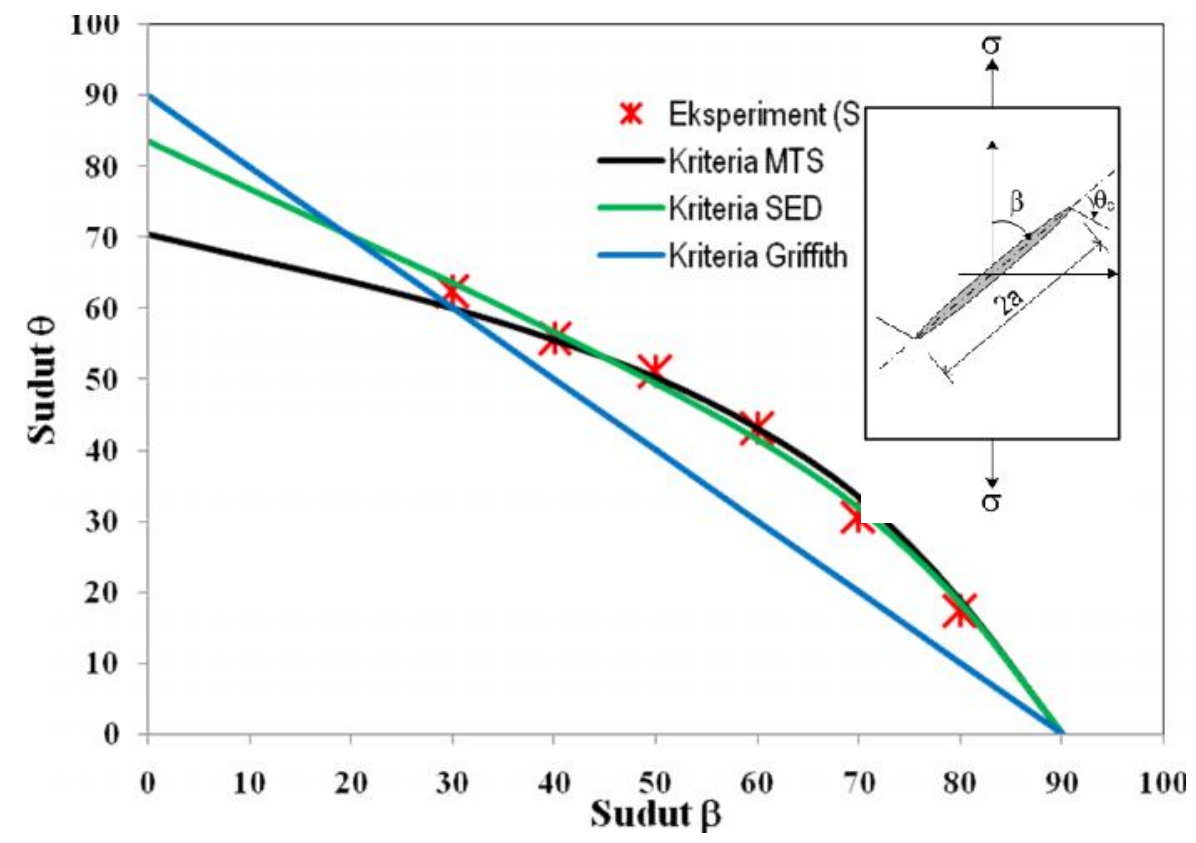

Gambar 12. Hubungan sudut $\beta$ dan $\theta$ Teoritik \& Eksperimental

Tabel 1 Hubungan sudut $\beta$ dan $\theta$ (Sih, 1973, N. Perez, 2004)

\begin{tabular}{||c|c|c|c|c||}
\hline \hline Sudut Retak $\beta$ & Eksperimen (Sih) & Pers. 21 (MTS) & Pers. 38a (SED) & Kriteria Griffith \\
\hline \hline 0 & & 70,53 & 83,62 & 90,00 \\
\hline 30 & 62,4 & 60,00 & 63,49 & 60,00 \\
\hline 40 & 55,6 & 55,65 & 56,66 & 50,00 \\
\hline 50 & 51,1 & 50,29 & 49,47 & 40,00 \\
\hline 60 & 43,1 & 43,22 & 41,49 & 30,00 \\
\hline 70 & 30,7 & 33,29 & 31,80 & 20,00 \\
\hline 80 & 17,3 & 18,91 & 18,49 & 10,00 \\
\hline 90 & & 0,00 & 0,00 & 0,00 \\
\hline \hline
\end{tabular}




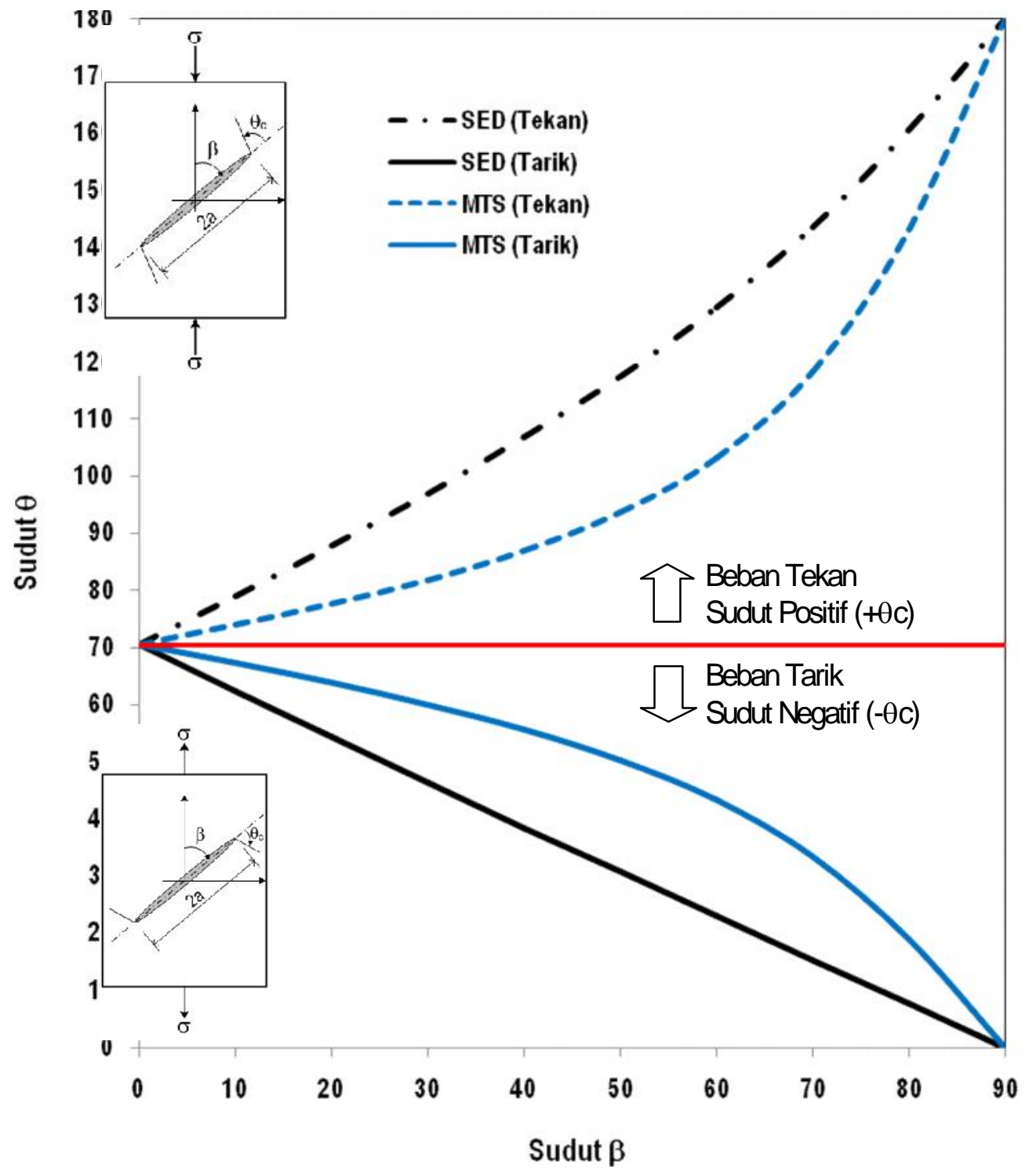

Gambar 13. Hubungan Sudut $\beta$ dan $\theta$ (Kasus Gaya Tekan \& Tarik)

\subsection{Contoh Kasus Beban Mode I dengan sudut retak $\beta$}

Pelat dengan panjang tak terbatas, panjang retak $2 a=100 \mathrm{~mm}$, membentuk sudut retak tan $=3 / 4$ seperti gambar dd. Diketahui $\mathrm{K}_{\mathrm{Ic}}=54 \mathrm{MPa} \sqrt{\mathrm{m}}$, Modulus Elastisitas $\mathrm{E}=200 \mathrm{GPa}$ dan $\mathrm{v}=0.25$ dengan kondisi pelat regangan bidang (plane strain). Komponen tegangan sehubungan dengan Mode I dan Mode II. 


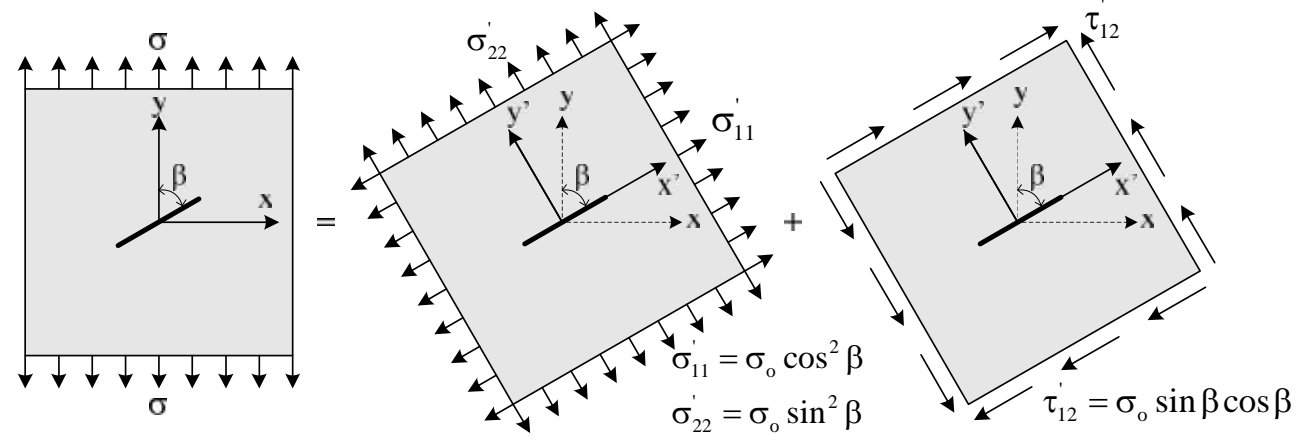

Gambar 14. Retak dengan sudut $\beta$ dibebani beban aksial tarik

$\mathrm{K}_{\mathrm{I}}=\sigma_{\mathrm{o}} \sqrt{\pi \mathrm{a}} \sin ^{2} \beta=\frac{9}{25} \sigma_{\mathrm{o}} \sqrt{\pi \mathrm{a}} \quad ; \quad \mathrm{K}_{\mathrm{II}}=\sigma_{\mathrm{o}} \sqrt{\pi \mathrm{a}} \sin \beta \cos \beta=\frac{12}{25} \sigma_{\mathrm{o}} \sqrt{\pi \mathrm{a}}$

i. Arah Penjalaran retak awal untuk $\tan \beta=3 / 4$.

Dengan menggunakan kriteria MTS sesuai pers. (21), maka diperoleh sudut kritis $\theta_{c}=-57,096^{\circ}$ ,dengan menggunakan kriteria SED sesuai pers. (39a), maka diperoleh sudut $\theta_{\mathrm{c}}=-55,413^{\circ}$.
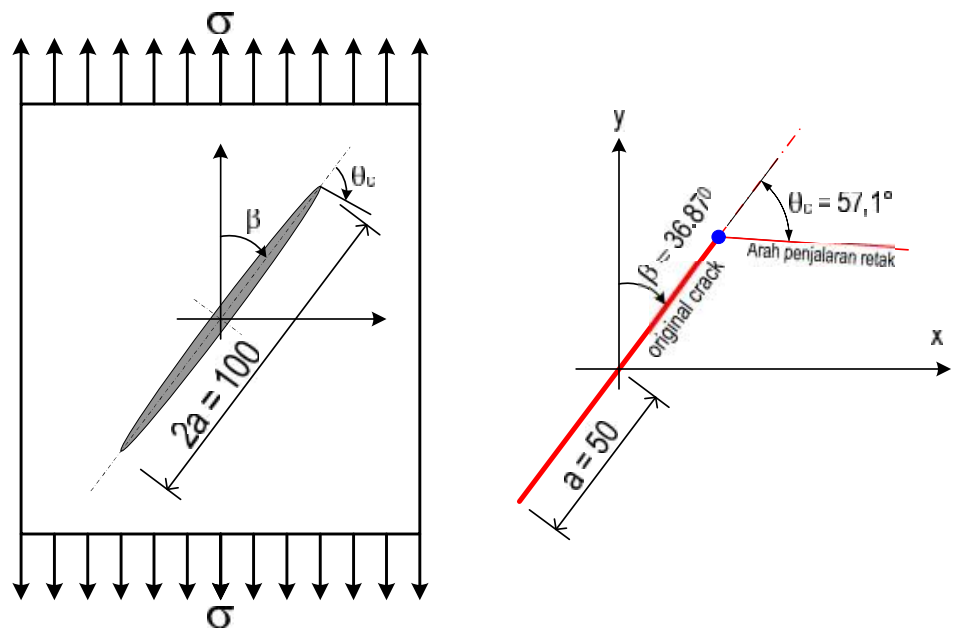

Gambar 15. Geometri retak serta arah penjalaran retak (crack branching)

\section{ii. Tegangan Kritis yang berhubungan dengan awal retak}

Dengan kriteria MTS sesuai dengan Persamaan (21) dan Pers. (25) maka diperoleh Tegangan kritisnya $\sigma_{0}^{\text {crit }}=175,803 \mathrm{MPa}$, sedangkan Tegangan kritis dengan kriteria SED sesuai persamaan (39a) dan Pers. (39b) dan diperoleh $\sigma_{0}^{\text {crit }}=214.726 \mathrm{MPa}$. 


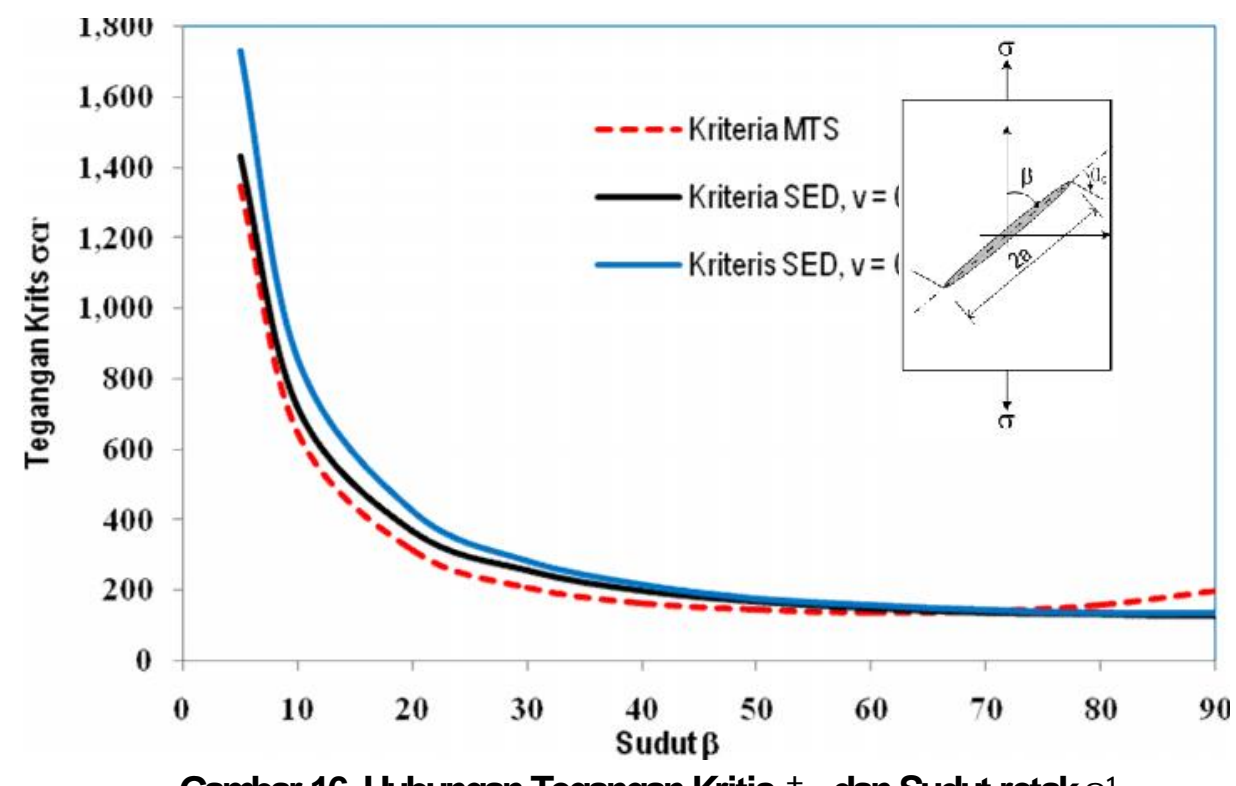

Gambar 16. Hubungan Tegangan Kritis $\sigma_{\mathrm{cr}}$ dan Sudut retak $\beta$

\section{KESIMPULAN}

Kriteria Tegangan Tangensial Maksimum (Maximum Tangential Stress, MTS) didasarkan pada fungsi tegangan dan analisanya tidak tergantung pada tegangan bidang dan regangan bidang. Untuk kriteria Kerapatan Energi Regangan (Strain Energy Density, SED) berhubungan dengan energi regangan dan oleh karena itu syarat-syarat untuk peramalan arah pertumbuhan retak serta tegangan kritis bergantung pada kondisi tegangan bidang dan regangan bidang. Pada kriteria MTS maupun kriteria SED, tegangan kritis $\left(\sigma_{c}\right)$, sudut kritis arah penjalaran retak $\left(\theta_{c}\right)$ dapat disebabkan tegangan tarik murni, tegangan geser dan kombinasi keduanya, tegangan biaxial serta dapat diperluas pada tegangan tekan dengan komponen yang mempunyai retak dengan sudut retak $(\beta)$.

Pada peramalan arah pertumbuhan retak serta tegangan kritis maka kriteria SED lebih baik untuk verifikasi terhadap hasil uji eksperimental dibandingkan kriteria MTS, hal ini karena dalam kriteria SED mengakomodir faktor pengaruh tegangan dan regangan bidang. 


\section{DAFTAR PUSTAKA}

Aliabadi, MH, Rooke, DP, 1991, Numerical Fracture Mechanics, Kluwer Academic Publisher, Netherlands.

Anderson, TL, 1995, Fracture Mechanics, Fundamentas and Applications, CRC Press, USA.

Barsom, John M. Rolfe, Stanley T. 1999, Fracture and Fatigue Control in Structures, ASTM

Bazant, Znedek P., Jaime, Planas, 1998, Fractures Size Effect, in Concrete and Other Quasibrittle Materials, CRS Press, USA.

Bazant, Znedek P., Cedolin, Luigi, 1991, Stability of Structures, Elastic, Inelastic, Fractures, and Damage Theories, Oxford University Press

Broek, David. 1986, Elementary Engineering Fracture Mechanics, Martinus Nijhoff Publishers Netherlands.

Dieter, George E, 1988, Mechanical Metallurgy, McGraw-Hill Inc, USA.

Hellan, Kare, 1985, Introduction to Fracture Mechanics, McGraw-Hill Inc, USA.

Kumar, Prasahant, 2009, Elements of Fracture Mechanics, Tata McGraw-Hill, India.

Owen, DRJ. Fawkes, AJ, 1983, Engineering Fracture Mechanics : Numerical Methods and Applications, Pineridge Press Limited, Swansea UK.

Patricio, M., Mattheij, MM Robert, Crack Propagation Analysis

Perez, Nestor, Fracture Mechanic, 2004 Kluwer Academic Publishers

Pikey, Walter D, 2005, Formulas for Stress, Strain, and Structural Matrices, John Wiley \& Sons Inc.

Rahman, MK, Hossain, MM, Rahman, SS, 2000, An Analytical Method for Mixed Mode Propagation of Pressurized Fractures in Remotely Compressed Rocks, International Journal of Fracture : 243 258,2000, Kluwer Academic Publishers, Netherlands.

Rajasekaran, S, 1986, Numerical Methods in Science and Engineering, A.H. Wheeler \& Co. Ltd, Allahabad, New Delhi, India.

Saouma, Victor E, 2000, Lecture Notes in : Fracture Mechanics, University of Colorado.

Sih, GC, 2008, Mechanics of Fracture Initiation and Propagation, Kluwer Academic Publisher.

Sih, GC, 2008, Multiscale Fatigue Crack Initiation and Propagation of Engineering Materials: Structural Integrity and Microstructural Worthiness, Springer Science Business Media.

Shah, P, Surendra, 1995, Fracture Mechanics of Concrete, John Wiley \& Sons.

Williams, JG, 1984, Fracture Mechanics of Polymer, Ellis Horwood, England.

Young, Warren C. 1989, Roarks Formula for Stress and Strain, Mc. Graw Hill. USA. 